\title{
MODELING MONTHLY AVERAGE DAILY DIFFUSE RADIATION FOR DHAKA, BANGLADESH
}

\author{
Debazit Datta $^{1}$, Utpal Kanti Das ${ }^{2}$, Saadia Binte Alam³ ${ }^{3}$, Md. Moksud Islam (Lalan) ${ }^{4}$ \\ ${ }^{1}$ Lecturer, Department of Quantitative sciences, International University of Business Agriculture and Technology, Uttara- \\ 10, Dhaka-1230,Bangladesh, ddatta@iubat.edu \\ ${ }^{2}$ Professor and Coordinator, Department of Computer Science and Engineering, International University of Business \\ Agriculture and Technology, Uttara-10, Dhaka-1230, Bangladesh, ukd@iubat.edu \\ ${ }^{3}$ Assistant Professor, Department of Electrical and Electronics Engineering, International University of Business \\ Agriculture and Technology, Uttara-10,Dhaka-1230,Bangladesh, saadia.alam@iubat.edu \\ ${ }^{4}$ Lecturer, Department of Quantitative sciences, International University of Business Agriculture and Technology, Uttara- \\ 10, Dhaka-1230, Bangladesh, mislam@iubat.edu
}

\begin{abstract}
The diffuse part of solar radiation is one of the elements necessary for the design and evaluation of energy production of a solar system. However, in most cases, when radiometric measurements are made, only global radiation is available. To remedy this situation, this paper presents a model of the scattered radiation measured on a horizontal surface for the capital city of Bangladesh. The correlation established for the chosen site was compared to the work of Liu anf Jordan, Page, Collares Pereira and Rabl, Modi and Sukhatme and Gupta el al.
\end{abstract}

Keywords: Diffuse Radiation, Clearness Index, Regression analysis, Horizontal Radiation.

\section{INTRODUCTION}

The split of total solar radiation on a horizontal surface into its beam and diffuse components is of interest in two contexts [1]. First, methods for calculating total radiation on surfaces of other orientation from data on a horizontal surface require separate treatments of beam and diffuse radiation. Second, estimates of the long time performance of most concentrating collectors must be based on estimates of availability of beam radiation.

The empirical procedure of Liu and Jordan [2] involves a one parameter correlation between the diffuse to global ratio and the clearness index, $K_{t}$.From a detailed statistical analysis, Liu and Jordan discovered that a firm relationship exists between $K_{t}$ and the diffuse fraction.

The literature abounds with studies attempting to check, improve and extend this empirical correlation approach. Several authors have compared the original Liu and Jordan results with similar correlations obtained in other geographical areas [3-6]. The diffuse fraction has also been correlated with the number of hours of sunshine [7] and a combination of $K_{t}$ and cloud cover.

In this study, we have developed statistic model of the solar radiation highlighting the direct relationship between global solar radiation and its diffuse component. Seven years (2003-
2010) of measured data of solar radiation were used for this purpose. The model is based on the clearness index $K_{t}$. Finally, the model obtained for Dhaka, Bangladesh is compared with already established models for different locations of the world to achieve the better accuracy of the model.

\section{MATHEMATICAL REVIEW}

Least squares regression is used to determine the line of best fit through the data points. The mathematical procedure for this method will now be reviewed.

Any curve which can be fit over a data set can be shown to be a function $y$ where

$$
y=f\left(x, a_{j}\right)
$$

Where $j=1,2,3 \ldots \ldots \ldots \ldots m$, with $j$ representing the number of coefficients required to create the curve of the specified order. For example, the 3 order equation can be expressed in the general form

$$
y_{i}=a_{1}+a_{2} x+a_{3} x^{2}+a_{4} x^{3}
$$


Where $a_{1}$ through $a_{4}$ are the unknown $a_{j}$ coefficients These coefficients can be found using the least squares regression method and matrix algebra.

The general formula for least squares regression is

$$
\sum_{i=1}^{n}\left(y_{i}-f\left(x_{i}, a_{1}, \ldots a_{m}\right)\right) \frac{\partial}{\partial a_{j}} f\left(x_{i}, a_{1}, \ldots a_{m}\right)=0
$$

The second half of (iii) can be simplified by taking the partial derivative of the terms, producing

$$
\begin{aligned}
\frac{\partial f}{\partial a_{j}}\left(x_{i}, a_{1}, \ldots a_{m}\right) & =\frac{\partial}{\partial a_{j}}\left[a_{1} g_{1}+a_{2} g_{2}+\cdots \ldots .+a_{m} g_{m}\right] \\
& =g_{i}\left(x_{i}\right) \quad(i v)
\end{aligned}
$$

After this partial differentiation, the general equation for least squares regression becomes

$$
\sum_{i=1}^{n}\left[y_{i}-a_{j} g_{i}\left(x_{i}\right)\right] g_{i}\left(x_{i}\right)=0
$$

From the general equation in $(v)$, the general form matrix can be built,

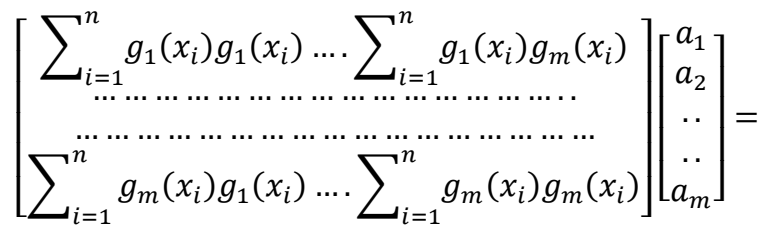

$$
\begin{aligned}
& =\left[\begin{array}{c}
\sum_{i=1}^{n} y_{i} g_{1}\left(x_{i}\right) \\
\cdots \cdots \cdots \cdots \\
\cdots \cdots \cdots \cdots \\
\sum_{i=1}^{n} y_{i} g_{m}\left(x_{i}\right)
\end{array}\right]
\end{aligned}
$$

Finally, by taking the $3^{\text {rd }}$ order equation identified in (ii) and defining the values of $g_{i}\left(x_{i}\right)$ as shown in (vii), the general form of the matrix can be populated and solved using linear algebra, so that

$$
\begin{aligned}
f\left(x_{i}, a_{1}, \ldots a_{4}\right)= & a_{1} g_{1}(x)+a_{2} g_{2}(x)+a_{3} g_{3}(x) \\
& +a_{4} g_{4}(x)(v i i)
\end{aligned}
$$

Where

$$
\begin{aligned}
& g_{1}(x)=1 \\
& g_{2}(x)=x \\
& g_{3}(x)=x^{2} \\
& g_{4}(x)=x^{3}
\end{aligned}
$$

\section{METHODOLOGY}

The extra terrestrial solar radiation on a horizontal surface $H_{0}$ is a function only of latitude and independent of other locational parameters. As the solar radiation passes through the earth's atmosphere, it is further modified by processes of scattering and absorption due to the presence of cloud and atmospheric particles. Hence, the daily global solar insulation incident on a horizontal surface $H$ is very much location specific and less than the extra terrestrial irradiation.

The original regression equation of order three related monthly average daily diffuse radiation to horizontal radiation at the location and average fraction of possible sunshine hours

$$
\frac{\overline{H_{d}}}{\bar{H}}=a_{1}+a_{2} \bar{K}_{t}+a_{3}{\overline{K_{t}}}^{2}+a_{4} \bar{K}_{t}^{-3}
$$

Where, $\bar{H}=$ monthly average daily radiation on a horizontal surface

Where, $\bar{H}_{d}=$ monthly average daily diffuse radiation

$a_{1}, a_{2}, a_{3}, a_{4}$ Empirical constants to be determined

$\bar{K}_{t}=$ Clearness index $=\frac{\bar{H}}{H_{0}}$

The horizontal radiation is determined by the following equation

$$
\frac{\bar{H}}{H_{0}}=a+b\left(\frac{\bar{n}}{\bar{N}}\right)
$$

$\bar{H}_{0}=$ Monthly average daily extraterrestrial radiation

$a, b=$ Angstrom's coefficients

$\bar{n}=$ Monthly average daily hours of bright sunshine

$\bar{N}=$ Monthly average of the maximum possible daily hours of sunshine or day length

The Angstrom coefficients determined for Dhaka are $a=$ $0.23, b=0.57[11]$

The extra terrestrial solar radiation on a horizontal surface is calculated from the following equation:

$H_{0}=\frac{24 \times 3600 \times I_{S C}}{\pi}\left(1+0.033 \cos \left(360 \frac{d}{365}\right)\right)$

Where, $I_{s c}=1367 \mathrm{Wm}^{-2}$ is the solar constant and $H_{0}$ is in $\mathrm{Jm}^{-2}$

$d$ is day number, $\phi$ is the latitude of the location, $\delta$ is the declination angle given by

$$
\delta=23.45 \sin \left(360 \frac{284+d}{365}\right)
$$

And $\omega$ is the sunset hour angle given by 


$$
\omega=\cos ^{-1}(-\tan \phi \tan \delta)
$$

The maximum possible sunshine duration $N$ is then given by

$$
N=\frac{2}{15} \omega
$$

In this paper $H_{0}$ and $N$ were computed for each month by using equations (3) and (5) respectively. The regression constants $a_{1}, a_{2}, a_{3}, a_{4}$ in equation (1) have been calculated from the values of $\frac{\overline{H_{d}}}{\bar{H}}$ and $\frac{\bar{H}}{H_{0}}$ using the least square regression equation (vi). The values of monthly average daily global radiation $H$ and the average number of hours of sunshine were obtained from daily measurements covering the period $1994-2010$. [12-13]

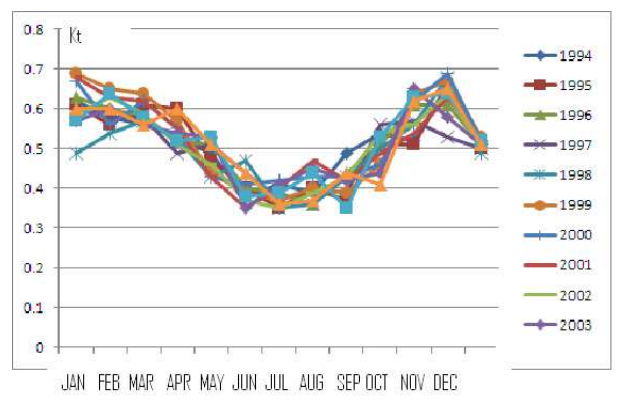

Fig 1: Clearness index versus months for the years 1994-2003 at Dhaka.

It is encouraging to note from figure 1 that the clearness index of Dhaka is within the interval $0.3 \leq \bar{K}_{t} \leq 0.7$ which indicates a clear sky throughout the year with exception in monsoon season (Jun-Sep) where clearness index goes to the minimum. The result of our model was compared with other previously stated models. The compared models are:

Page: the correlation equation which is widely used is developed by Page:

$$
\frac{H_{d}}{H}=1-1.13 K_{t}
$$

Liu and Jordan [2] using available daily radiation data for Blue hill, Massachusetts, USA have shown the following correlation

$$
\frac{H_{d}}{H}=1.39-4.027 K_{t}+5.53 K_{t}^{2}-3.108 K_{t}^{3}
$$

Collares- Pereira and Rabl[10]: equations representing this set of correlations are as follows

For $\omega_{s} \leq 81.4^{0}$ and $0.3 \leq K_{t} \leq 0.8$

$$
\frac{H_{d}}{H}=1.391-3.56 K_{t}+4.189 K_{t}^{2}-2.137 K_{t}^{3}
$$

For $\omega_{s}>81.4^{0}$ and $0.3 \leq K_{t} \leq 0.8$

$$
\frac{H_{d}}{H}=1.311-3.022 K_{t}+3.427 K_{t}{ }^{2}-1.821 K_{t}{ }^{3}
$$

for Indian stations where the diffuse radiation is much higher compared to US stations, the linear correlations as proposed by Modi and Sukhatme [8] and Gupta et al [9] are respectively.

Modi and Sukhatme:

$$
\frac{H_{d}}{H}=1.411-1.696 K_{t}
$$

\section{Gupta et al:}

$$
\frac{H_{d}}{H}=1.354-1.57 K_{t}
$$

Model for Dhaka: this study proposes the following model for Dhaka, Bangladesh:

$$
\frac{H_{d}}{H}=1.0016-1.0064 K_{t}-00.3475 K_{t}^{2}+0.0165 K_{t}^{3}
$$

\section{RESULTS AND DISCUSSION}

From the measured and estimated values of diffuse solar radiation it is seen that the contribution of diffuse radiation is very small (on average $27 \%$ ) throughout the year with the exception of the monsoon months (on average 58\%).

To validate the models established for Dhaka, it is necessary to compare it those proposed by other authors. For this purpose, we performed statistical tests on the estimated values of the diffuse fraction of the solar radiation obtained with each model considered in this study using the measured data of the local site which are taken as a reference for the comparison.

The first test is a simplified comparison of the composite Residual Sum of Squares (CRSS), defined by

$$
C R S S=\sum\left[\left(H_{d} / H\right)_{e s t}-\left(H_{d} / H\right)_{m e s}\right]^{2}
$$

The second test is to calculate the Mean Bias Error (MBE) given by

$$
M B E=\frac{\sum\left[\left(H_{d} / H\right)_{e s t}-\left(H_{d} / H\right)_{m e s}\right]}{m}
$$

The third test is to determine the correalation coefficient $r$ between estimated and measured radiation values given by 


$$
r=\frac{\sum\left(\left(H_{d} / H\right)_{e s t}-\overline{H_{e}}\right)\left(\left(H_{d} / H\right)_{m e s}-\overline{H_{m}}\right)}{\sqrt{\sum\left(\left(H_{d} / H\right)_{e s t}-\overline{H_{e}}\right)^{2} \sum\left(\left(H_{d} / H\right)_{m e s}-\overline{H_{m}}\right)^{2}}}
$$

Where, $\bar{H}_{e}$ is the arithmetic mean value of the $m$ estimated values of the global solar diffuse radiation, $\bar{H}_{m}$ is the arithmetic mean value of the $m$ measured values.

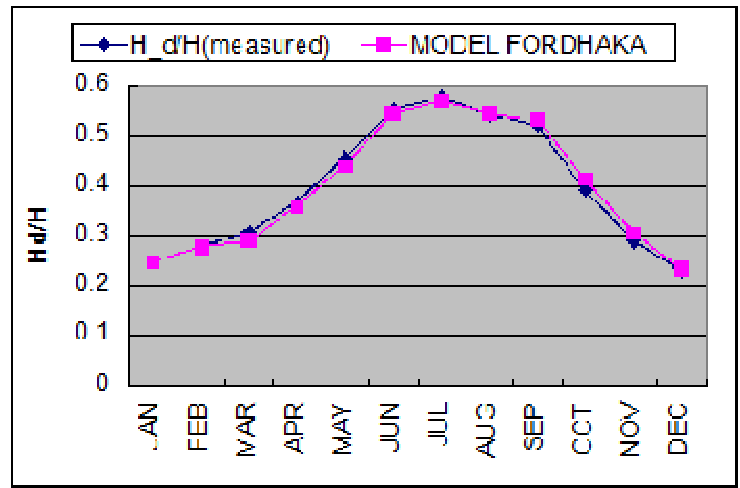

Fig 2: diffuse fraction vs months for measured and Dhaka model

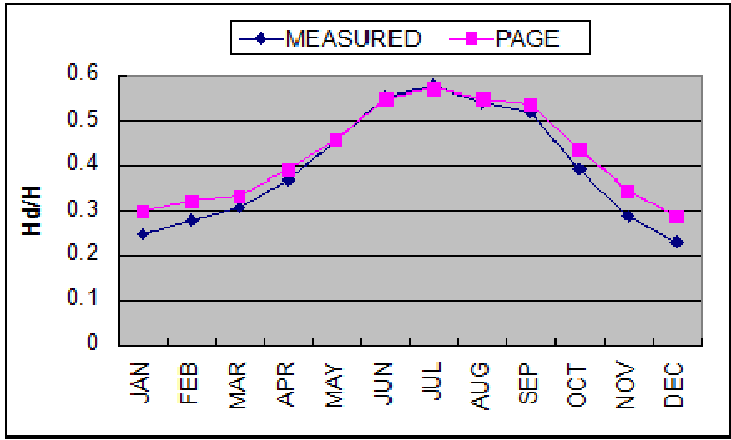

Fig 3: diffuse fraction vs months for measured and Page model

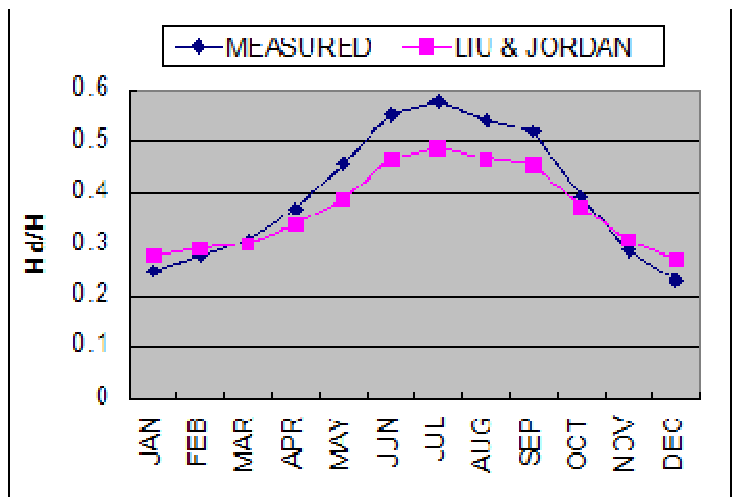

Fig 4: diffuse fraction vs months for measured and Liu \& Jordan model
Table 1: Ratio of diffuse radiation to global radiation by applying different models

\begin{tabular}{|c|c|c|c|c|c|c|c|}
\hline $\begin{array}{l}3 \\
2 \\
Z \\
Z \\
3\end{array}$ & 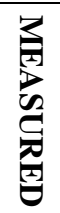 & 党 & $\overrightarrow{2}$ & 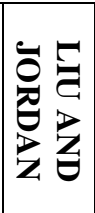 & 可 & 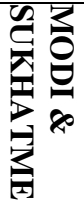 & $\sum \underset{D}{\stackrel{2}{7}}$ \\
\hline JA & 0.2 & 0.24 & 0.2 & 0.2 & 0.2 & 0.3 & 0.3 \\
\hline $\mathrm{N}$ & 47 & 7 & 99 & 78 & 84 & 59 & 81 \\
\hline $\mathrm{FE}$ & 0.2 & 0.27 & 0.3 & 0.2 & 0.3 & 0.3 & 0.4 \\
\hline B & 78 & 6 & 22 & 93 & 01 & 93 & 12 \\
\hline MA & 0.3 & 0.29 & 0.3 & 0.3 & 0.3 & 0.4 & 0.4 \\
\hline $\mathrm{R}$ & 07 & 0 & 33 & 01 & 09 & 10 & 27 \\
\hline AP & 0.3 & 0.35 & 0.3 & 0.3 & 0.3 & 0.4 & 0.5 \\
\hline $\mathrm{R}$ & 68 & 9 & 89 & 38 & 54 & 95 & 06 \\
\hline MA & 0.4 & 0.44 & 0.4 & 0.3 & 0.4 & 0.5 & 0.6 \\
\hline $\mathrm{Y}$ & 56 & 0 & 57 & 87 & 11 & 96 & 00 \\
\hline $\mathrm{JU}$ & 0.5 & 0.54 & 0.5 & 0.4 & 0.5 & 0.7 & 0.7 \\
\hline $\mathrm{N}$ & 51 & 4 & 48 & 65 & 00 & 32 & 26 \\
\hline $\mathrm{JU}$ & 0.5 & 0.56 & 0.5 & 0.4 & 0.5 & 0.7 & 0.7 \\
\hline $\mathrm{L}$ & 76 & 9 & 71 & 87 & 25 & 66 & 57 \\
\hline $\mathrm{AU}$ & 0.5 & 0.54 & 0.5 & 0.4 & 0.5 & 0.7 & 0.7 \\
\hline $\mathrm{G}$ & 41 & 4 & 48 & 65 & 00 & 32 & 26 \\
\hline $\mathrm{SE}$ & 0.5 & 0.53 & 0.5 & 0.4 & 0.4 & 0.7 & 0.7 \\
\hline $\mathrm{P}$ & 18 & 1 & 36 & 54 & 88 & 15 & 10 \\
\hline $\mathrm{OC}$ & 0.3 & 0.41 & 0.4 & 0.3 & 0.3 & 0.5 & 0.5 \\
\hline $\mathrm{T}$ & 91 & 3 & 35 & 70 & 91 & 63 & 69 \\
\hline $\mathrm{NO}$ & 0.2 & 0.30 & 0.3 & 0.3 & 0.3 & 0.4 & 0.4 \\
\hline $\mathrm{V}$ & 87 & 4 & 44 & 08 & 18 & 27 & 43 \\
\hline $\mathrm{DE}$ & 0.2 & 0.23 & 0.2 & 0.2 & 0.2 & 0.3 & 0.3 \\
\hline $\mathrm{C}$ & 31 & 3 & 88 & 70 & 76 & 42 & 64 \\
\hline
\end{tabular}

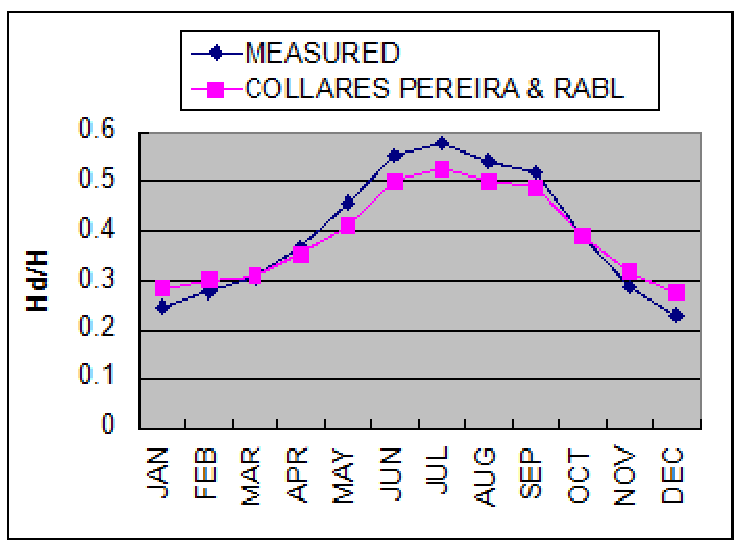

Fig 5: diffuse fraction vs months for measured and Collares Pereira \& Rabl model 


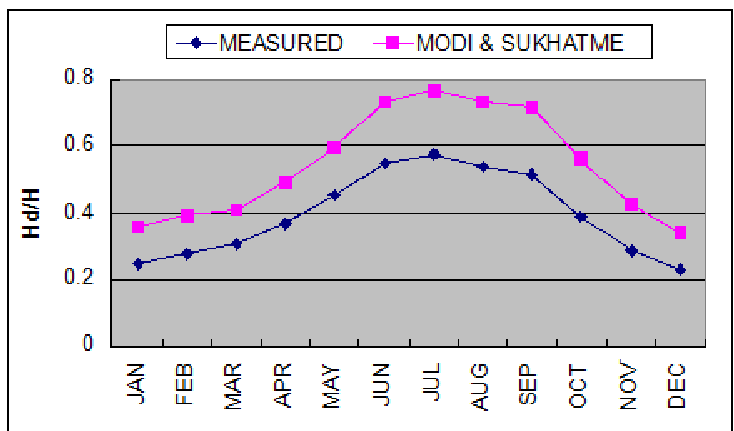

Fig 6: diffuse fraction vs months for measured and Modi \& Sukhatme model

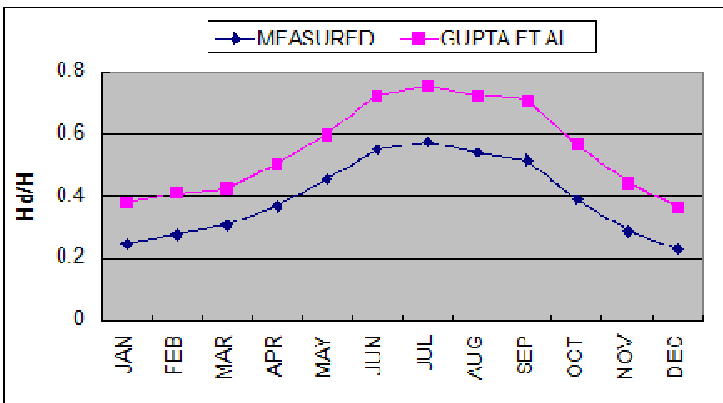

Fig 7: diffuse fraction vs months for measured and Gupta et al model

Analyzing the figures 2-7, it is seen that the best fit of diffuse radiation is due to model for Dhaka (figure 2). A little difference is observed in Page and Collares Pereira \& rabl model whereas Modi \& Sukhatme and Gupta et al models do not suit the measured data of diffuse radiation at Dhaka at all.

Table 2: Statistical test results of different models

\begin{tabular}{|l|l|l|l|}
\hline MODEL & MBE \% & CRSS & $\mathrm{R}^{\wedge} 2$ \\
\hline $\begin{array}{l}\text { DHAKA } \\
\text { MODEL }\end{array}$ & -0.000048 & 0.000144 & 0.990401 \\
\hline PAGE \& & 0.220411 & 0.001221 & 0.990397 \\
\hline $\begin{array}{l}\text { LIU JORDAN } \\
\text { JOR }\end{array}$ & -0.233188 & 0.002891 & 0.987077 \\
\hline $\begin{array}{l}\text { COLLARES } \\
\text { P PEREIRA }\end{array}$ & -0.065224 & 0.001256 & 0.986896 \\
\hline $\begin{array}{l}\text { MODI \& } \\
\text { SUKHATME }\end{array}$ & 1.2359803 & 0.023164 & 0.990397 \\
\hline $\begin{array}{l}\text { GUPTA ET } \\
\text { AL }\end{array}$ & 1.297355 & 0.024803 & 0.990397 \\
\hline
\end{tabular}

From table 2 it is seen that the MBE is the lowest among all the models and is almost nearly zero. CRSS for Dhaka, Bangladesh is minimum than any other exixting models which implies the best suit for the local site. Also the Coefficients of Determination is maximum and is nearly equal to unity.

\section{CONCLUSIONS}

Taking into account the differences in climatic conditions specific to each terrestrial hemisphere it is imperative to develop models for the sites of each hemisphere. This study shows that the model developed is more adaptive to the local site than those established for the northern hemisphere. This model can help the sizing and the evaluation of the solar energy systems with a great accuracy for the local region.

\section{REFERENCES:}

[1]. Duffie J.A., and Beckman. W.A., 1980, Solar Engineering of Thermal processes, John Wiley and Sons, New York.

[2]. B.Y.H. Liu and R.C. Jordan, the interrelationship and characteristic distribution of direct diffuse and total solar radiation, Solar energy, 1960, 4(3), 1-19.

[3]. D. W. Ruth and R.E. Chant, the relationship of Diffuse radiation to total radiation in Canada, Solar Energy 18, 153154, (1976).

[4]. S.E. tuller, the relationship between diffuse, total and extra terrestrial solar radiation, solar energy, 18, 259-263 (1976)

[5]. N.K.D Choudhury, Solar Radiation at New Delhi. Solar Energy, 7, 44(1963).

[6]. M. Collares-Pereira and A. Rabl, the average distribution of solar radiation correlations between diffuse and hemispherical and daily and hourly insolation values, solar energy 22, 155-164 (1979).

[7]. M Iqbal , estimation of the monthly average of the diffuse component of total insolation on a horizontal surface, solar energy, 20, 101-106 (1978).

[8]. Vijay Modi and S.P.Sukhatme, Estimation of daily total and diffuse insolation in India from weather data, Solar energy, 1979, 22, 407.

[9]. C. L. Gupta, K. Usha Rao and T. A. Reddy, radiation design data for solar energy applications, Energy Management, 1979, 3, 299.

[10]. Collares Pereira, M and A. Rabl, Solar Energy, 22, 155 (1979a), The Average Distribution of Solar radiation Correlations between Diffuse and Hemispherical and between Daily and Hourly Insolation Values.

[11]. Debazit Datta, Bimal Kumar Datta, Empirical model for the estimation of global solar radiation in Dhaka, Bangladesh, International Journal of Research in Engineering and Technology, Vol 2, Issue 11, Nov 2013, pp-649-653.

[12]. NASA Surface Meteorology and Solar Energy: Inter Annual Variability

[13]. Bangladesh Meteorology Department.

[14]. R.J. Stone, Improved statistical procedure for the evaluation of solar radiation estimation models, Solae energy, Vol 51, pp. 289-291, 1993.

[15]. J.F. Orgill and K. G. T. Hollands, Correlation equation for hourly diffuse radiation on horizontal surface, Solar Energy, Vol 19, n 4, pp. 357-359, 1977. 